\title{
DEA Window Analysis with slack-based measure of Efficiency in Indian Cement Industry
}

\author{
Arif Muhammad*, Tirupathi Rao and Qaiser Farooq \\ Department of Statistics, Ramanujan School of Mathematical Sciences, Pondicherry University, India.
}

\begin{abstract}
In data envelopment analysis (DEA), the concept of efficiency is examined either in radial measure or in nonradial measure. Radial measure gives the proportion or a percentage by which all the inputs (outputs) to be reduced(increased) simultaneously, while as the non-radial measure deals directly with the input output slacks which must be minimized, hence inputs and outputs need not to optimized by same proportion. Radial measures often provide a weak efficiency score while as there is no such case for Non-radial models. The aim of this paper is to employ the non-radial measure(Slack-based model) in DEA window analysis to measure the Technical Efficiency change over years of various Indian cement companies. The research is based on unbalanced panel data of Indian cement companies during the period 2005-15. DEA window analysis is used to determine the efficiency of cement companies and to observe the possibility of changes in the technical efficiency over time. A study is conducted to evaluate the efficiency of cement companies in India in order to identify the sources of inefficiencies and formulate proposals for improving the productivity of those companies and their operations through a three-year window analysis.
\end{abstract}

Keywords Data Envelopment Analysis, Non-Radial Models, Slack-Based Measure, DEA Window Analysis, Indian Cement companies

\section{AMS 2010 subject classifications 90C15,68C05}

DOI: $10.19139 /$ soic.v6i2.360

\section{Introduction}

The aim of this paper is to evaluate the Technical efficiency change over time from the period 2005 to 2015 of various Indian cement companies by employing extended Data Envelopment Analysis (DEA) approach. As conventional DEA models evaluates efficiency for a particular period and fails in cross sectional and time varying data, this paper employed an extended DEA approach, specifically DEA window analysis for the efficiency assessment of cement companies of India over the defined period. On the other hand there are two basic approaches of DEA one is Radial approach and other Non-Radial approach. In Radial approach all inputs and outputs are to be optimized (Depends upon the orientation of the problem) by the same specified proportion to become efficient, while in non-radial approach this proportion is different from one output to another or one input to another. For example, in radial case, if there are three inputs and two outputs, then in input orientation if the efficiency score comes to be 0.90 by solving the corresponding programming problem, then the evaluated DMU has to reduce all inputs by 10 percent in input orientation case, while in non-radial case three inputs can be reduced by different proportions. If the DMUs are on optimal scale (scale efficient), then both approaches will give same value, otherwise non-radial measure is better than radial one. Since the cement companies are not working on optimal scale, it is good to use some non-radial method to evaluate the efficiency. A DMU which comes to be efficient at a

\footnotetext{
*Correspondence to: Arif Muhammad (Email: arif9dea@gmail.com, Mob: +91 9486153394) Statistics,Ramanujan School of Mathematical
} Sciences, Pondicherry University-605014, India.

ISSN 2310-5070 (online) ISSN 2311-004X (print)

Copyright (C) 2018 International Academic Press 
particular time period may or may not be efficient for other period. Both of above mentioned methods deals with particular period, and van not be used in time varying and cross section data to estimate the efficiency change over different time periods. To estimate the efficiency change over time a method was proposed by [6] and called it as DEA Window Analysis Approach. This method based on radial approach evaluates the efficiency change of DMUs over time. Here in this study, we proposed a non-radial model called as Slack-based model (SBM) for window analysis Approach. The SBM model was first proposed by [24]. We proposed the SBM model for window analysis methodology, to estimate non-radial efficiency change over time. Later we applied the proposed the DEA window analysis based on the Slack-Based Model (SBM) to measure SBM efficiency change over time 2005-15 of various Indian cement companies. The contribution should be able to see the companys efficiency evolves over time and to see whether any size effect exists in the cement company efficiency. This analysis provides trends of efficiency and the rank of each cement company evaluated in terms of its effectiveness. The obtained results allow for analyses of trends of the overall cement sector efficiency. By this approach, the SBM efficiency is analyzed sequentially with a certain window width (i.e. the number of years in a window) using a panel data of the Indian Cement companies. The main idea is to capture the temporal impact on cement efficiency and see its short-run evolution from one window to another.

The remainder of this paper unfolds as follows. Next section describes the empirical literature about cement companies of India and some literature on Window analysis. Third section presents the methodology of SBM DEA with window analysis. Section four describes the data analysis of cement companies. last part includes the conclusion of the paper.

\section{Literature survey}

In recent times cement has become second most consumed substance after water. it is produced from limestone, shell and clay and processed on the temperature of more than 1000 degree Celsius. it is the main ingredient of construction. without it concrete construction is impossible. so utmost care should be taken to improve this industry. off course this industry release a large amount of $\mathrm{CO}_{2}$ especially in china and India, which is an undesirable output and should be taken into consideration while trying to maximize the production. To achieve high growth rates of GDP in a sustainable manner, India has to place much emphasis on the growth of its manufacturing sector.The objective of the Indian planners is to achieve accelerated growth in the industrial sector (especially manufacturing) with a view to increasing industry's share in GDP as well as India's share in the worlds industrial output. However,the indigenous Indian cement industry traces its history back to 1914, at the time the market was dominated by imports.Today, the Indian cement industry is very large and second to China in terms of installed capacity. Figure (1) shows the cement production of India in 2013 and its estimated value in 2020.

Fig. 1: Cement Production

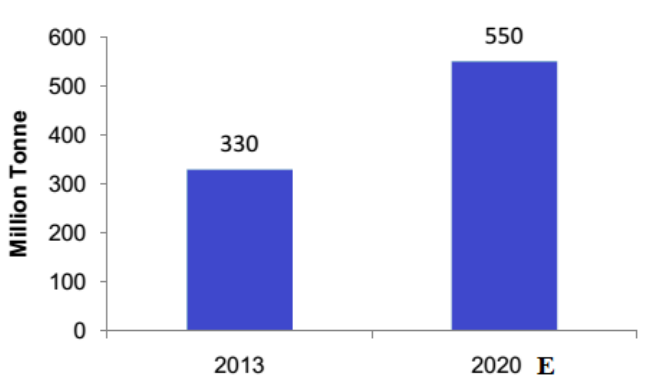

It has grown at a very fast pace in recent years. Since 1992 India's cement production has more than quadrupled from around 50Mt/yr to $220 \mathrm{Mt} / \mathrm{yr}$. The Indian cement industry is now globally competitive with lowest energy consumption and $\mathrm{CO}_{2}$ emissions. Apart from fulfilling domestic cement requirements, the industry also exports cement and clinker to around 30 countries across the globe. As per of 2011 there were 137 large and 367 mini cement plants in India. In this study we have selected 28 leading producers in order to measure their energy 
intensity, which is the quantity of energy used per nit of output. A large amount of literature is available for examining energy intensity of cement industries. [16] estimates the environmental efficiency with $\mathrm{CO}_{2}$ as undesirable output for interstate data. Their results shows that indian cement industry has a potential to expand desirable outputs and contract undesirable outputs with the given inputs. [17] measures the energy efficiency of Indian cement industry and estimates the factors explaining inter-firm variations between the periods 1989-90 to 2006-07. [3] used a complete decomposition technique to decompose the sectoral changes in energy consumption and energy intensity in India during 1980C1996. Their study reveals that though there was an improvement in aggregate energy intensity, the agricultural sector was lagging behind. [12] used several DEA models for measuring energy use efficiency of the manufacturing sectors in USA and India.[22] uses the double frontier approach in two-stage DEA case to evaluate the efficiency of various commercial banks through SBM models. [9] used mixed orientation approach to find the efficiency of Decision Making Units. There is a rich body of research to examine energy intensity across various sectors. There are so many ways to examine the efficiency of a production process, but the way DEA finds the efficiency it has gained popularity in energy efficiency analysis.

[4] devleloped a non-parametric model the relative efficiency of DMUs producing same outputs using same inputs. This model evaluates the efficeincy for a perticular time perio, and hence can not used in case of cross sectional and time varying data. Obtaing Technical efficiency for time varying data and evaluating efficiency change over time was the concern to researchers. [6] orginaaly proposed DEA Window Analysis approach as a method to evauate efficiency change in cross sectional and time varying data. Later so many studies were done on window analysis to estimate the efficiency change. For example, [18] applies the DEA window analysis window analysis on the data of the Czech commercial banks and to examine the efficiency of the Czech banking sector during the period 2003C2012. In their analysed period, the average efficiency under constant return to scale reached 70C78 $\%$ and average efficiency under variable return to scale reached 84C89\%. Similarly, [11] measure the efficiency of East and West African major ports over time by using the Data Envelopment Analysis (DEA) Window Analysis. The analysis revealed total average efficiency level of ports of each of the two regions being below $80 \%$, it means that these ports are in general not really efficient. The ports with the lowest level of efficiency should expand their customer base and increase the public and private investment. This approach has been applied almost in all profit and non-profit organizations. [28] examines the operating efficiency of U.S. hotels with various types, geographic locations, sizes, and room rates from a dynamic perspective by analyzing the efficiency stability and trend from year 2007 to year 2014. [1] evaluates the energy efficiency and productivity growth in the industrial sector over the period of 1999 till 2013 using DEA Window Analysis. DEA Window Analysis was also applied in the cases were outputs are undesirables, as [27] focused on evaluation of Chinas regional total-factor energy and environmental efficiency within a joint production framework of considering both desirable and undesirable outputs, as well as energy and non-energy inputs. DEA window analysis is employed in some of these instances but when the study horizon is long and the DMUs environment is heavily effected by technological change, one should use a Malmquist index approach as well. [2] used this approach to deal with the less number of DMUs for efficiency evaluation of Canadian Banking Industry for the period of 1981-2000. Usual DEA gives the efficiency only for a given year, but in case of panel data we can not use DEA for detecting efficiency within a given interval of time. Thus, it is useful in detecting performance trends of a decision making unit over time. Each DMU is treated as a different unit in a different period which can increase the number of data point. But the model used is a radial measure given by [4]. Here we are using non-radial measure of DEA, i.e., SBM model with window analysis.

\section{Slack-Based Model in DEA}

Data envelopment analysis is a mathematical programming technique that measures the efficiency of a decisionmaking units (DMUs) relative to other similar DMUs with the simple restriction that all DMUs lie on or below the efficiency frontier [19]. There are two types of models to measure the efficiency of DMUs, one is Radial and another is non-radial. Radial models are represented by the CCR (Charnes-Cooper-Rhodes) model [4]. Basically they deal with proportional changes of inputs or outputs. As such, the CCR score reflects the proportional 
maximum input (output) reduction (expansion) rate which is common to all inputs (outputs). However, in real world businesses, not all inputs (outputs) behave in the proportional way. Another drawback of the radial models is the neglect of slacks in reporting the efficiency score. So, if these slacks have an important role in evaluating managerial efficiency, the radial approaches may mislead the decision when we utilize the efficiency score as the only index for evaluating performance of DMUs. This drawback of radial models is eliminated by non-radial models.

In contrast, the non-radial SBM models put aside the assumption of proportionate changes in inputs and outputs, and deal with slacks directly. This may discard varying proportions of original inputs and outputs. The SBM models are designed to meet the following two conditions.

(1) Units invariant: The measure should be invariant with respect to the units of data

(2) Monotone: The measure should be monotone decreasing in each slack in input and output.

This model was was introduced by [24] which directly deals with input and output slacks in DEA. Unlike the additive DEA model [5],[24] SBM gives the efficiency score between the interval of zero and one. Further,[25]presents a super-efficiency model for decision making units (DMUs) that are efficient under SBM so that efficient DMUs can be ranked. This model has been widely used to find the non-radial efficiency. [29] developed two slack-based efficiency measures for modeling environmental performance on the basis of environmental DEA technology. Of the two measures, one is a composite index with a higher discriminating power for modeling economicCenvironmental performance, and the other can be used to estimate the impacts of environmental regulations. Since original DEA models are proposed to identify efficient performers in the most favorable scenario. For the purpose of identifying bad performers such as bankrupt firms in the most unfavorable scenario,radial worst-practice frontier DEA model has been proposed [14], they further developed HypoSBM model to distinguish the worst performers from the bad ones. Efficiency of Indian commercial banks was obtained by [20] For estimating the potential reductions and efficiency of $\mathrm{CO} 2$ emissions for China,[8] used the slack-based measure of efficiency for potential reductions and efficiency of $\mathrm{CO}_{2}$ emissions for China and its dual for estimating the marginal abatement costs of energy-related $\mathrm{CO}_{2}$ emissions. A two-stage approach of slack-based model for super efficiency has been proposed by [10]. In fuzzy environment various slack-based models were proposed [21]. In network analysis a lot of research has been done with SBM measures [13], [15],[23] This model is having the structure as: Suppose we have a set of 'n' DMUs denoted by $\mathrm{j}(\mathrm{j}=1, \ldots, \mathrm{n})$ each having ' $m$ ' inputs and 's' outputs. Let the input and output vectors of $D M U_{j}$ be $X_{j}=\left(x_{1 j}, x_{2 j}, \ldots, x_{m j}\right)^{T}$ and $Y_{j}=\left(y_{1 j}, y_{2 j} \ldots, y_{s j}\right)^{T}$ respectively. Then input and output matrices can be represented as

$$
\mathbf{X}=\left(X_{1}, X_{2}, \ldots, X_{n}\right) \in \Re^{m * n} \text { and } \mathbf{Y}=\left(Y_{1}, Y_{2}, \ldots Y_{n}\right) \in \Re^{s * n}
$$

The production possibility set $\mathbf{P}$ is given by;

$$
P=\left\{(X, Y) \mid X \geq \sum_{j=1}^{n} \lambda_{j} X_{j}, Y \leq \sum_{j=1}^{n} \lambda_{j} Y_{j}, \lambda \geq 0\right\}
$$

$\lambda=\left(\lambda_{1}, \lambda_{2}, \ldots, \lambda_{n}\right)$ is called the intensity vector. The production possibility set shows that $\mathrm{Y}$ can be produced by $\mathrm{X}$ if $\mathrm{X}$ is no less than the linear combination of inputs of other DMUs and $\mathrm{Y}$ is no greater than the linear combination of other outputs. The inequalities in the set can be transformed into equalities by introducing slacks as follows:

$$
\begin{aligned}
& X=\sum_{j=1}^{n} \lambda_{j} X_{j}+s^{-} \\
& Y=\sum_{j=1}^{n} \lambda_{j} Y_{j}-s^{+} \\
& s^{-} \geq 0, s^{+} \geq 0
\end{aligned}
$$


Where $\mathbf{s}^{-}=\left(s_{1}^{-}, s_{2}^{-}, \ldots, s_{m}^{-}\right)^{T}$ and $\mathbf{s}^{+}=\left(s_{1}^{+}, s_{2}^{+}, \ldots, s_{s}^{+}\right)^{T}$ are input and output slacks respectively. The ratio $\left(x_{i o}-s_{i}^{-}\right) / x_{i o}$ evaluates the relative reduction rate of input $i$ and $1 / m \sum_{i=1}^{m}\left(x_{i o}-s_{i}^{-}\right) / x_{i o}$ is called mean reduction rate. Similarly $\left(y_{r o}+s_{r}^{+}\right) / r_{r o}$ evaluates the relative expansion rate of $r^{t h}$ output and $1 / s \sum_{r=1}^{s}\left(y_{r o}+s_{r}^{+}\right) / y_{r o}$ is corresponding mean expansion rate, and its inverse output inefficiency. The product of these two inefficiencies can be interpreted as SBM $\rho$.

$$
\begin{aligned}
\rho_{o}= & \left(\frac{1}{m} \sum_{i=1}^{m} \frac{\left(x_{i o}-s_{i}^{-}\right)}{x_{i o}}\right)\left(\frac{1}{s} \sum_{r=1}^{s} \frac{\left(y_{r o}+s_{r}^{+}\right)}{y_{r o}}\right)^{-1} \\
= & \frac{1}{\frac{1}{s} \sum_{i=1}^{m} \frac{\left(x_{i o}-s_{i}^{-}\right)}{x_{i o}}} \\
= & \frac{1-\frac{1}{m} \sum_{i=1}^{m} \frac{\left.s_{i o}^{-}+s_{r}^{+}\right)}{y_{i o}}}{1+\frac{1}{s} \sum_{r=1}^{s} \frac{s_{r}^{+}}{y_{r o}}}
\end{aligned}
$$

Equation (3) is the SBM efficiency and was given by Tone 2001 subject to the constraints given in (2). Thus the actual SBM model given by [24]

$$
\min \rho_{o}=\frac{1-\frac{1}{m} \sum_{i=1}^{m} \frac{s_{i}^{-}}{x_{i o}}}{1+\frac{1}{s} \sum_{r=1}^{s} \frac{s_{r}^{+}}{y_{r o}}}
$$

sub to

$$
\begin{aligned}
& x_{i o}=\sum_{j=1}^{n} \lambda_{j} x_{i j}+s_{i}^{-} \\
& y_{r o}=\sum_{j=1}^{n} \lambda_{j} y_{r j}-s_{r}^{+} \\
& s^{-} \geq 0, s^{+} \geq 0
\end{aligned}
$$

Definition (1): A DMU is said to SBM efficient if its corresponding $\rho=0$. This means $s_{i}^{-}=0, \forall i$ and $s_{r}^{+}=0, \forall r$.

The above model is in non-linear form and hence can be transformed into linear form by applying charnes cooper 
transformation as:

$$
\min \tau^{*}=t-\frac{1}{m} \sum_{i=1}^{m} \frac{S_{i}^{-}}{x_{i o}}
$$

sub to

$$
\begin{aligned}
& t+\frac{1}{s} \sum_{r=1}^{s} \frac{S_{r}^{+}}{y_{r o}}=1 \\
& t x_{i o}=\sum_{j=1}^{n} \Lambda_{j} x_{i j}+S_{i}^{-} \quad(i=1, \ldots, m) \\
& t y_{r o}=\sum_{j=1}^{n} \Lambda_{j} y_{r j}-S_{r}^{+} \quad(r=1, \ldots, s) \\
& S_{i}^{-} \geq 0(\forall i), S_{r}^{+} \geq 0(\forall r), \Lambda_{j} \geq 0(\forall j)
\end{aligned}
$$

Let the optimal solution of the above linear programming is $\left[\tau^{*}, t^{*}, \Lambda^{*}, \mathbf{S}^{-*}, \mathbf{S}^{+*}\right]$.Then we have optimal solution of the problem (4) as:

$$
\rho^{*}=\tau^{*}, \lambda^{*}=\Lambda^{*} / t, \mathbf{s}^{-*}=\mathbf{S}^{-*} / t, \mathbf{s}^{+*}=\mathbf{S}^{+*} / t
$$

If $\rho^{*}=\tau^{*}=1$ then the corresponding DMU is said to be SBM efficient, and by this condition all slacks are zero, Otherwise, it is said to be inefficient. This model is solved for each DMU in order to find its efficiency. Thus we have to solve $\mathrm{n}$ problems to find the efficiency of $\mathrm{n}$ DMUs in a given period of time. But in case of panel data we have to solve so many problems depends on the size of window and number of DMUs. The window analysis is done in the following procedure.

\section{Window Analysis with Slack-Based Model}

In order to capture the variations of efficiency over time, [6] has proposed a technique called Window Analysis in DEA. The window analysis assesses the performance of a DMU over time by treating it as a different entity in each time-period. This method allows for tracking the performance of a unit or DMU over time and provides a better degree of freedom. If a DMU is found to be efficient in one year despite the window in which it is placed, it is likely to be considered strongly efficient compared to its peers. Suppose we have n DMU as taken in above models with same input and output matrix, but we have the data for $T(d=1, \ldots, T)$ periods. Then $D M U_{n}^{d}$ represents an observation $n$ in period $d$ with $m$ dimensional input vector and $s$ dimensional output vector as;

$$
x_{n}^{d}=\left[\begin{array}{c}
x_{n}^{1 d} \\
\vdots \\
x_{n}^{m d}
\end{array}\right] ; y_{n}^{d}=\left[\begin{array}{c}
y_{n}^{1 d} \\
\vdots \\
y_{n}^{s d}
\end{array}\right]
$$

If a widow starts at time period $k(1 \leq k \leq T)$ with a window width $w(1 \leq w \leq T-k)$ Then matrices of inputs and outputs are denoted as follows:

$$
X_{k w}=\left[\begin{array}{ccccc}
x_{1}^{k} & x_{2}^{k} & x_{3}^{k} & \ldots & x_{n}^{k} \\
x_{1}^{k+1} & x_{2}^{k+1} & x_{3}^{k+1} & \ldots & x_{n}^{k+1} \\
\vdots & \vdots & \vdots & \ddots & \vdots \\
x_{1}^{k+w} & x_{2}^{k+w} & x_{3}^{k+w} & \ldots & x_{n}^{k+w}
\end{array}\right] ; \quad Y_{k w}=\left[\begin{array}{ccccc}
y_{1}^{k} & y_{2}^{k} & y_{3}^{k} & \ldots & y_{n}^{k} \\
y_{1}^{k+1} & y_{2}^{k+1} & y_{3}^{k+1} & \ldots & y_{n}^{k+1} \\
\vdots & \vdots & \vdots & \ddots & \vdots \\
y_{1}^{k+w} & y_{2}^{k+w} & y_{3}^{k+w} & \ldots & y_{n}^{k+w}
\end{array}\right]
$$


Substituting inputs and outputs of $D M U_{n}^{t}$ into Models will produce the results of DEA window analysis. The SBM model of DEA window problem for $D M U_{d}^{k}$ is given by solving the following linear program:

$$
\operatorname{Min} \rho_{o}^{k}=\frac{1-\frac{1}{m^{k}} \sum_{i=1}^{m^{k}} \frac{s_{i}^{(-, k)}}{x_{i o}^{k}}}{1+\frac{1}{s^{k}} \sum_{r=1}^{s^{k}} \frac{s_{r}^{(+, k)}}{y_{r o}^{k}}}
$$

Sub to

$$
\begin{aligned}
& x_{i o}^{k}=\sum_{j=1}^{n} \lambda_{j}^{k} x_{i j}^{k}+s_{i}^{(-, k)} \\
& y_{r o}^{k}=\sum_{j=1}^{n} \lambda_{j}^{k} y_{r j}^{k}-s_{r}^{(+, k)} \\
& s^{(-, k)} \geq 0, s^{(+, k)} \geq 0
\end{aligned}
$$

The model (7) is slack-based model for $k^{t h}$ window in non-linear form. The same can be transformed into linear programming problem by applying Charnes cooper transformation. let us put the following transformation in model (7);

$$
\begin{aligned}
& t=\frac{1}{1+\frac{1}{s^{k}} \sum_{r=1}^{s^{k}} \frac{s_{r}^{(+, k)}}{y_{r o}^{k}}} \\
& t s_{i}^{(-, k)}=S_{i}^{(-, k)} \\
& t s_{r}^{(+, k)}=S_{r}^{(+, k)} \\
& t \lambda_{j}^{k}=\Lambda_{j}^{k}
\end{aligned}
$$

By substituting these values in the model (7), a new model will be formed in terms of linear programming problem, which is as follows;

$$
\begin{aligned}
& \min \tau_{t}^{k *}=t-\frac{1}{m^{k}} \sum_{i=1}^{m^{k}} \frac{S_{i}^{k-}}{x_{i o}^{k}} \\
& \text { sub to } \\
& t+\frac{1}{s} \sum_{r=1}^{s} \frac{S_{r}^{k+}}{y_{r o}^{k}}=1 \\
& t x_{i o}^{k}=\sum_{j=1}^{n} \Lambda_{j} x_{i j}^{k}+S_{i}^{k-}(i=1, \ldots, m) \\
& t y_{r o}^{k}=\sum_{j=1}^{n} \Lambda_{j} y_{r j}^{k}-S_{r}^{k+}(r=1, \ldots, s) \\
& S_{i}^{k-} \geq 0(\forall i), S_{r}^{k+} \geq 0(\forall r), \Lambda_{j} \geq 0(\forall j)
\end{aligned}
$$

Model (9) is applied for every window to estimate the technical efficiency for each DMU. The windows are made on the basis of moving average method, that is one DMU is coming and one DMU leaves the system. The procedure of making windows is elaborated in the succeeding section. 


\section{Data and Selection of Variables}

As it is already mentioned above that window analysis deals with cross sectional and time varying data. This cross sectional is to formed in windows with a certain window length based on moving averages. As there is no theory or justification that underpins the definition of the window size, this paper utilizes a three-year window, which is consistent with the original work by [6]. Furthermore, in most often studies, window length has been take either as three or four. If the number of years are more, then window length of four will be favorable to reduce the number of windows, otherwise three is preferable in most of cases.

To illustrate, from Table 1, the first window incorporates years 2005, 2006 and 2007. When a new period is introduced into the window, the earliest period is dropped. In window two, year 2005 will be dropped and year 2008 will be added to the window. Subsequently in window 3, years 2007, 2008 and 2009 will be assessed. The analysis is performed until window 9 analyses years 2013, 2014 and 2015. As DEA window analysis treats a DMU as different entity in each year, a three-year window with twenty eight DMUs is equivalent to 84 DMUs. Subsequently, by applying a 9, three-year window, would considerably increase the number of observations of the sample to 783 , providing a greater degree of freedom.

Table 1. Windows Breakdown

\begin{tabular}{lllllllllllll}
\hline \hline window 1 & 2005 & 2006 & 2007 & & & & & & & & \\
window 2 & 2006 & 2007 & 2008 & & & & & & & \\
window 3 & & 2007 & 2008 & 2009 & & & & & & \\
window 4 & & & 2008 & 2009 & 2010 & & & & & \\
window 5 & & & & 2009 & 2010 & 2011 & & & & \\
window 6 & & & & & 2010 & 2011 & 2012 & & & \\
window 7 & & & & & & 2011 & 2012 & 2013 & & \\
window 8 & & & & & & & 2012 & 2013 & 2014 & \\
window 9 & & & & & & & & 2013 & 2014 & 2015 \\
\hline
\end{tabular}

The data set used in this paper was obtained from the database Centre for Monitoring Indian Economy (CMIE) and the annual reports of Indian cement companies for the period 11 years from 2005C2015. The descriptive statistics of the variables (three inputs and one output) are given in the Table 2

Table 2. DESCRIPTIVE STATISTICS OF VARIABLES

\begin{tabular}{|c|c|c|c|c|c|}
\hline & $\begin{array}{l}\text { Power, Fuel } \\
\& \text { Water Charges }\end{array}$ & $\begin{array}{l}\text { raw Materials } \\
\text { Stores \& Spares }\end{array}$ & $\begin{array}{l}\text { Compensation } \\
\text { to Employees }\end{array}$ & $\begin{array}{l}\text { Miscellaneous } \\
\text { Expenditure }\end{array}$ & $\begin{array}{l}\text { Net } \\
\text { Sales }\end{array}$ \\
\hline Mean & 5091.39 & 4187.49 & 139.73 & 1735.77 & 26646.75 \\
\hline Median & 2472.90 & 1910.15 & 494.05 & 485.60 & 11301.55 \\
\hline Max & 46875.60 & 34941.10 & 12248.60 & 23118.20 & 260210.70 \\
\hline Min & 8.70 & 4.10 & 22.80 & 5.50 & 0.30 \\
\hline St. Dev. & 6694.27 & 5689.11 & 1926.38 & 207.88 & 34092.18 \\
\hline
\end{tabular}

In this paper, the data set comprises of 28 cement companies. As we have reliable data extracted directly from annual reports, we eliminate the risk that incomplete or biased data may distort the estimation results. In order to conduct SBM DEA window analysis estimation,inputs and outputs need to be defined. Here we have employed four inputs as: 1) Power, fuel and water charges 2) Raw materials, stores and spares 3) Compensation to employees 4) Miscellaneous expenditure and the only output as Net sales. Here we adopted DEA window analysis SBM (slack based model C non-radial) models that can evaluate the overall efficiency of decision-making units for the period from 2005-15. For empirical analysis we used DEA solver a add-on option in Microsoft excel where we solved as many as linear problem as number of DMUs in each window.The results of the SMB 
Table 3. EFFICIENCY OF CEMENT COMPANIES IN DIFFERENT WINDOWS

\begin{tabular}{|c|c|c|c|c|c|c|c|c|c|}
\hline DMUs & $\begin{array}{l}2005 \\
-2007\end{array}$ & $\begin{array}{l}2006 \\
-2008\end{array}$ & $\begin{array}{l}2007 \\
-2009\end{array}$ & $\begin{array}{l}2008 \\
-2010\end{array}$ & $\begin{array}{l}2009 \\
-2011\end{array}$ & $\begin{array}{l}2010 \\
-2012\end{array}$ & $\begin{array}{l}2011 \\
-2013\end{array}$ & $\begin{array}{l}2012 \\
-2014\end{array}$ & $\begin{array}{l}2013 \\
-2015\end{array}$ \\
\hline Ultratech & 0.710 & 0.825 & 0.743 & 0.789 & 0.787 & 0.841 & 0.837 & 0.859 & 1.000 \\
\hline A C C Ltd. & 0.677 & 0.726 & 0.668 & 0.726 & 0.746 & 0.726 & 0.711 & 0.718 & 0.739 \\
\hline Ambuja cem. & 0.727 & 0.763 & 0.679 & 0.720 & 0.756 & 0.738 & 0.751 & 0.749 & 0.768 \\
\hline Shree cem. & 0.832 & 0.919 & 0.710 & 0.851 & 0.884 & 0.857 & 0.784 & 0.919 & 0.827 \\
\hline Prism cem. & 0.707 & 0.698 & 0.651 & 0.778 & 0.832 & 0.820 & 0.830 & 0.873 & 1.000 \\
\hline India Cem & 0.622 & 0.752 & 0.763 & 0.677 & 0.633 & 0.597 & 0.634 & 0.752 & 0.597 \\
\hline Ramco Cem & 1.000 & 1.000 & 0.734 & 0.782 & 0.965 & 0.938 & 0.874 & 0.890 & 0.958 \\
\hline J K Cem & 0.645 & 0.673 & 0.655 & 0.744 & 0.708 & 0.689 & 0.696 & 0.727 & 0.699 \\
\hline Birla Corp & 0.496 & 0.533 & 0.536 & 0.615 & 0.718 & 0.660 & 0.617 & 0.695 & 0.590 \\
\hline OCL India & 1.000 & 1.000 & 0.638 & 0.686 & 0.734 & 0.716 & 0.702 & 0.717 & 0.816 \\
\hline JK Lakshmi & 0.529 & 0.560 & 0.537 & 0.607 & 0.643 & 0.661 & 0.727 & 0.794 & 0.801 \\
\hline Heidelberg & 0.507 & 0.570 & 0.479 & 0.580 & 0.784 & 0.764 & 0.691 & 0.781 & 0.706 \\
\hline Mangalam & 0.609 & 0.642 & 0.604 & 0.698 & 0.767 & 0.706 & 0.698 & 0.742 & 0.645 \\
\hline K C P & 0.472 & 0.530 & 0.511 & 0.487 & 0.471 & 0.524 & 0.621 & 0.664 & 0.588 \\
\hline Saurashtra & 0.454 & 0.488 & 0.498 & 0.589 & 0.654 & 0.682 & 0.731 & 0.722 & 0.701 \\
\hline Shree Dig. & 0.523 & 0.545 & 0.481 & 0.549 & 0.678 & 0.766 & 0.841 & 0.680 & 0.553 \\
\hline Gujarat Sid. & 1.000 & 1.000 & 1.000 & 1.000 & 1.000 & 1.000 & 0.695 & 0.619 & 0.599 \\
\hline Andhra Cem & 0.499 & 0.538 & 0.544 & 0.574 & 0.632 & 0.487 & 0.443 & 1.000 & 0.601 \\
\hline Bara & 0.622 & 0.644 & 0.537 & 0.566 & & 0.570 & 0.545 & 0.520 & 0.541 \\
\hline Panyam Cem & 0.562 & 1.000 & 1.000 & 1.000 & 1.000 & 1.000 & 1.000 & 1.000 & 1.000 \\
\hline Rain Cem & 1.000 & 1.000 & 1.000 & 1.000 & 1.000 & 1.000 & 1.000 & 1.000 & 1.000 \\
\hline Jaiprakash & 1.000 & 1.000 & 1.000 & 1.000 & 1.000 & 1.000 & 1.000 & 1.000 & 1.000 \\
\hline Chettinad & 0.697 & 0.756 & 0.748 & 0.846 & 0.864 & 0.747 & 0.768 & 0.755 & 1.000 \\
\hline Prism Cem & 0.707 & 0.698 & 0.651 & 0.778 & 0.832 & 0.820 & 0.830 & 0.863 & 1.000 \\
\hline Sanghi Indus. & 1.000 & 0.869 & 0.840 & 1.000 & 1.000 & 1.000 & 1.000 & 1.000 & 1.000 \\
\hline Binani Cem & 0.813 & 1.000 & 1.000 & 1.000 & 1.000 & 1.000 & 1.000 & 1.000 & 1.000 \\
\hline Century Text. & 0.480 & 0.537 & 0.506 & 0.533 & 0.545 & 0.533 & 0.540 & 0.535 & 0.565 \\
\hline MyHome ind. & 1.000 & 1.000 & 1.000 & 1.000 & 1.000 & 0.917 & 1.000 & 1.000 & 1.000 \\
\hline Mean & 0.710 & 0.759 & 0.706 & 0.759 & 0.797 & 0.770 & 0.772 & 0.802 & 0.813 \\
\hline
\end{tabular}

DEA efficiency scores during the period 2005-2015 are presented in Table (2). we have taken the window width of three years because [7] found that $w=3$ or 4 tended to yield the best balance of in formativeness and stability of the efficiency scores. In order to be sure that the results will be credible, a narrow window width must be used. Therefore, a 3 year window has been chosen in this paper. During the period 2005-15 the average SBM efficiency calculated ranges from $71 \%$ to $81 \%$. This average efficiency shows the frontier shift in various windows. It indicated how technology has changed during the given period. It can be seen from the table that technology is increasing from intial period to the end except the two periods 2007-09 and 2010-12. This development shows that indian cement companies are on average considered to be efficient, with only marginal changes over time. The results show that the average efficiency was highest in 2013-15 and lowest in 2007-09. Two companies whish were efficient in all windows were Rain cements and Jaiprakash cements. 


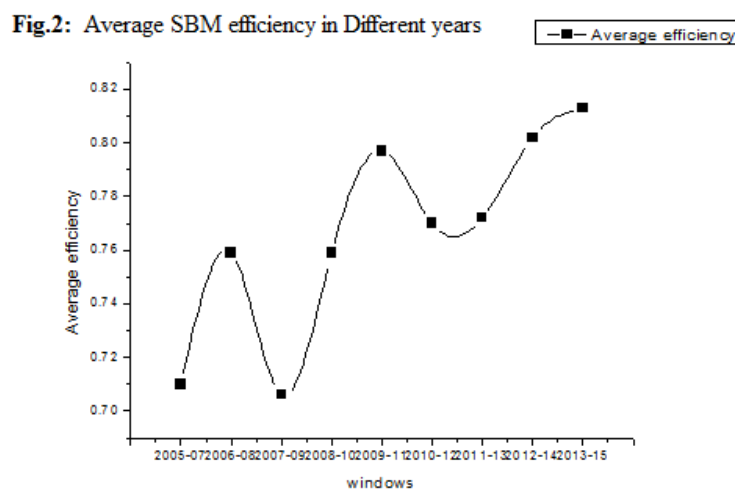

The figure (2) shows the trend of average SBM efficiencies during the given period. It can be seen from the figure(2) that on an average there is a upward(positive) direction of frontier. The highest efficiency is in the last window. After solving linear problems we find values of slacks mostly of input slacks. It was found that most of cases there was so much slacks in inputs especially raw materials and power,fuel and water. Theses are the main causes which are responsible for the inefficiency of the firms.

\section{Conclusion}

The aim of this paper is to estimate the efficiency of the Indian cement industry employing the Data Envelopment Analysis (DEA) window analysis approach during the period 2005-2015. It is the first application of the DEA window analysis approach on the Indian cement Industry. The research was based on unbalanced panel data for the period from 2005 to 2015. In this study we applied the DEA window analysis based on an non-radial slack-based model to measure relative efficiency of indian cement companies. We found two companies i.e., Rain cements and Jaiprakash cements which were efficient in all windows. On contrary, many cement companies were found efficient in one window and inefficient in other. The mean of efficiencies given in last row of table (2) shows the frontier displacement, to see the technological change in all the years. The results of the paper is that whereas during the period 2005-2006 the average efficiency was increasing, then in 2007-09 the average efficiency decreased and after that it began to increase till 2009-11, and then again fell down little bit in 2010-12, after that it starts increasing till end. For all cement companies it is important to examine the strategic plan for improving the operations, better use of capacities of plants and search tools to improve the service of these cement plants. Progress is made in the measurement of cement company efficiency in relation to port productive activities. In our study there were positive slacks in both inputs and outputs, but the slacks were more in inputs as compared to outputs. Thus in order to increase their productivity and efficiency they have reduce their inputs considerably.

\section{Acknowledgement}

Authors are grateful to an anonymous referee of this journal for the most constructive observations, and suggestion, which materially improved this paper.

\section{REFERENCES}

1. Al-Refaie, A., Hammad, M., and Li, M. H., DEA window analysis and Malmquist index to assess energy efficiency and productivity in Jordanian industrial sector, Energy Efficiency, 9(6), 1299-1313. 2016

2. Asmild, M., Paradi, J. C., Aggarwall, V., and Schaffnit, C. Combining DEA window analysis with the Malmquist index approach in a study of the Canadian banking industry, Journal of Productivity Analysis, 21(1), 67-89, 2004 
3. Bhattacharya, R. N., and Paul, S. Sectoral changes in consumption and intensity of energy in India, Indian Economic Review, 381-392, 2001

4. Charnes, A., Cooper, W. W., and Rhodes, E. Measuring the efficiency of decision making units, European journal of operational research, 2(6), 429-444, 1978.

5. Charnes, A., Cooper, W. W., Seiford, L., and Stutz, J. A multiplicative model for efficiency analysis, Socio-Economic Planning Sciences, 16(5), 223-224, 1982

6. Charnes, A., Clark, C. T., Cooper, W. W., and Golany, B. A developmental study of data envelopment analysis in measuring the efficiency of maintenance units in the US air forces, Annals of Operations Research, 2(1), 95-112, 1984.

7. Charnes, A., Cooper, W. W., Lewin, A. Y., and Seiford, L. M. (Eds.). Data envelopment analysis: Theory, methodology, and applications, Springer Science \& Business Media,2013. (2013).

8. Choi, Y., Zhang, N., and Zhou, P. Efficiency and abatement costs of energy-related $\mathrm{CO}_{2}$ emissions in China: a slacks-based efficiency measure, Applied Energy, 98, 198-208,2012.

9. Dar, Q. F., Padi, T. R., and Tali, A. M. Mixed input and output orientations of Data Envelopment Analysis with Linear Fractional Programming and Least Distance Measures, Statistics, Optimization \& Information Computing, 4(4), 326-341, 2016.

10. Fang, H. H., Lee, H. S., Hwang, S. N., and Chung, C. C. A slacks-based measure of super-efficiency in data envelopment analysis: An alternative approach, Omega, 41(4), 731-734, 2013.

11. Gamassa, P. K. P. O., and Chen, Y. (2017, June). Comparison of port efficiency between Eastern and Western African ports using DEA Window Analysis, In Service Systems and Service Management (ICSSSM), 2017 International Conference on (pp. 1-6). IEEE, 2017.

12. Mukherjee, K. Energy use efficiency in the Indian manufacturing sector: an interstate analysis, Energy policy, 36(2), 662-672, 2008.

13. Li, Y., Wang, Y. Z., and Cui, Q. Evaluating airline efficiency: an application of virtual frontier network SBM, Transportation Research Part E: Logistics and Transportation Review, 81, 1-17, 2015.

14. Liu, F. H. F., and Chen, C. L. The worst-practice DEA model with slack-based measurement, Computers \& Industrial Engineering, 57(2), 496-505, 2009.

15. Lozano, S. Alternative SBM model for network DEA Computers \& Industrial Engineering, 82, 33-40, 2015.

16. Mandal, S. K., \& Madheswaran, S. Environmental efficiency of the Indian cement industry: an interstate analysis, Energy Policy, 38(2), 1108-1118, 2010.

17. Mandal, S. K., \& Madheswaran, S. Energy use efficiency of Indian cement companies: a data envelopment analysis, Energy Efficiency, 4(1), 57-73, 2011.

18. Repkova, I. Efficiency of the Czech banking sector employing the DEA window analysis approach, Procedia Economics and Finance, 12, 587-596, 2014.

19. Seiford, L. M., and Thrall, R. M. Recent developments in DEA: the mathematical programming approach to frontier analysis, Journal of econometrics, 46(1), 7-38, 1990.

20. Shaban, M., Kavida, V., and Shah, A. Evaluating Efficiency of Commercial Banks in India: Using DEA Model, pacific business review international, volume 5, issue 9, page 9-18, 2013.

21. Shermeh, H. E., Najafi, S. E., and Alavidoost, M. H. A novel fuzzy network SBM model for data envelopment analysis: A case study in Iran regional power companies, Energy, 112, 686-697, 2016.

22. Tali, A. M., Padi, T. R., and Dar, Q. F. DEA Double Frontier in Two-Stage Processes with Slack-Based Measure, Int. J. Modern Mgmt. Sci, 5(1), 23-36, 2016.

23. Tavassoli, M., Faramarzi, G. R., and Saen, R. F. Efficiency and effectiveness in airline performance using a SBM-NDEA model in the presence of shared input, Journal of Air Transport Management, 34, 146-153, 2014.

24. Tone, K. A slacks-based measure of efficiency in data envelopment analysis, European journal of operational research, 130(3), 498-509, 2001.

25. Tone, K. A slacks-based measure of super-efficiency in data envelopment analysis, European journal of operational research, 143(1), 32-41, 2001.

26. Seiford, L. M., and Zhu, J. Profitability and marketability of the top 55 US commercial banks, management science, 45(9), 1270$1288,1999$.

27. Wang, K., Yu, S., and Zhang, W. Chinas regional energy and environmental efficiency: A DEA window analysis based dynamic evaluation, Mathematical and Computer Modelling, 58(5), 1117-1127, 2013.

28. Xu, X., and Chi, C. G. Q. Examining Operating Efficiency of US Hotels: A Window Data Envelopment Analysis Approach, Journal of Hospitality Marketing \& Management, (just-accepted), 2017.

29. Zhou, P., Ang, B. W., and Poh, K. L. Slacks-based efficiency measures for modeling environmental performance, Ecological Economics, 60(1), 111-118, 2006. 